\title{
Factors Related to Rejection of Care and Behaviors Directed towards Others: A Longitudinal Study in Nursing Home Residents with Dementia
}

\author{
Francisca Galindo-Garre ${ }^{a}$ Ladislav Volicerc, d Jenny T. van der Steen ${ }^{b}$ \\ a Department of Epidemiology and Biostatistics, and ${ }^{b}$ EMGO Institute for Health and Care \\ Research, Department of General Practice and Elderly Care Medicine, VU University Medical \\ Center, Amsterdam, The Netherlands; ' CSchool of Aging Studies, University of South Florida, \\ Tampa, Fla., USA; ${ }^{d}$ Charles University 3rd Medical Faculty, Prague, Czech Republic
}

Key Words

Rejection of care $\cdot$ Depression · Dementia $\cdot$ Psychosis $\cdot$ Pain $\cdot$ Nursing homes

\begin{abstract}
Aims: The aim of this study was to analyze factors related to rejection of care and behaviors directed towards others in nursing home residents with dementia. Methods: The relationship of lack of understanding, depression, psychosis and pain with rejection of care and behaviors directed towards others was explored using four assessments from the Minimum Data Set (MDS) within a period of 15 months on 1,101 residents with dementia in Dutch nursing homes. Presence of depressive symptoms was ascertained using a validated MDS scale, and presence of lack of understanding, rejection of care, psychosis and pain through the individual MDS items. A structural equation modeling approach and latent growth models were used to investigate the longitudinal relationship between changes in rejection of care and physical or verbal behaviors directed towards others, and changes in lack of understanding, pain, depression and psychotic symptoms. Results: Changes in lack of understanding predicted changes in rejection of care, and there was also a relationship between changes in depression and rejection of care. Changes of behaviors directed towards others were related to changes in lack of understanding and depression. Pain and behaviors directed towards others were unrelated, and psychosis was rather stable throughout. A mediation model suggested that the relationship of lack of understanding with behaviors directed towards others was mediated by rejection of care. Conclusion: These results indicate that lack of understanding and depression are important factors in development of rejection of care and behaviors directed towards others. The relationship between lack of understanding and behaviors directed towards others is mediated by rejection of care. Improvement in communication between residents and caregivers, and perhaps also effective treatment of depression may prevent or ameliorate these behaviors directed towards others.
\end{abstract}




\section{Introduction}

The course of progressive dementias may be characterized as a gradual loss of independence. Development of apraxia and other cognitive deficits requires help of others with activities of daily living. Unfortunately, the person with dementia sometimes does not cooperate with family or professional caregivers but actually resists care or exhibits behaviors during care that may be labeled abusive [1]. These behaviors may be difficult to handle by family caregivers and may lead to institutionalization $[2,3]$. In an institution, rejection of care and behaviors directed towards others may lead to injuries of the resident or staff and to staff burnout. A survey of nursing home physicians showed that the most common problem that they treated in residents with dementia was rejection of care [4].

There are several studies that investigated methods for management of behavioral symptoms of dementia. Some of them investigated the effectiveness of pain control [5], others used personalized psychosocial interventions based on the unmet needs theory [6] for treatment of agitation and found positive results. However, the problem with these studies is that they consider all behavioral symptoms to be agitation and do not differentiate between agitation and rejection of care. This is due to using the Cohen-Mansfield Agitation Inventory [7] or Neuropsychiatric Inventory [8] in which the item Agitation/Aggression is actually measuring rejection of care [9]. Similar problems are also present in drug trials investigating effects of antipsychotics and other medications $[10,11]$. Therefore, we decided to study specifically rejection of care that is a highly relevant problem in clinical practice [12].

We have previously described strong correlations between rejection of care and lack of understanding, depression and psychotic symptoms [13]. Behaviors directed towards others were strongly correlated with rejection of care, depression and delusions. However, these findings were based only on cross-sectional data. In this study, we performed longitudinal analyses to further explore the relationships of these modifiable factors with rejection of care and behaviors directed towards others of nursing home residents. Our hypothesis was that longitudinal data would support causal relationships between these modifiable factors and rejection of care.

\section{Material and Methods}

\section{Subject Population}

We used Minimum Data Set-Resident Assessment Instrument (MDS-RAI) data collected by 8 Dutch nursing homes and 10 residential homes. We included the data of residents within a 12-month time window for each facility separately, resulting in a range from April 4, 2007, to December 1, 2008. Of the records of 2,705 residents available from the 18 facilities, we selected the last records of 1,101 residents aged over 65 with Alzheimer or other dementia (I1q or $\mathrm{u}$ ), who were dependent in decision making (B4 not equal 0) and who were not comatose (B1 equal 0) [14]. Four assessments from the MDS within a period of 15 months were used for the analyses. Four assessments were completed for all patients.

\section{Measurements}

For rejection of care, we used the MDS 2.0 item 'resist care' (E4eA). The terminology was changed by the introduction of MDS 3.0, which uses 'rejection of care' instead of 'resist care'. Other new, but equivalent, items in MDS 3.0 are 'physical behavioral symptoms directed towards others' instead of 'physical abuse' and 'verbal behavioral symptoms directed towards others' instead of 'verbal abuse' [15]. We use the new terminology in this article. 
Presence of rejection of care and behavioral symptoms directed towards others was obtained from MDS 2.0 section E with choices from 'not exhibited' to 'daily'. The variables 'physical behavioral symptoms directed towards others' (E4cA) and 'verbal behavioral symptoms directed towards others' (E4bA) were combined into one variable called 'behaviors directed towards others'. Ability to understand (C6) was rated as 'always', 'usually', 'sometimes' and 'rarely/never'. Psychotic symptoms [delusions (J1e) and hallucinations (J1i)] were combined into one variable, 'psychosis', whose values are number of symptoms.

Clinical diagnosis of depression was obtained from MDS item I1ee, and depression symptoms were assessed by the validated Depression Rating Scale using other MDS items: negative statements (E1a), anger (E1d), unrealistic fears (E1f), repetitive health complaints (E1i), sad expression (E1I) and crying (E1m; score 0-14) [16]. Presence of depression was indicated by a score of 3 or higher. This scale correlated well with the Cornell and Hamilton depression scales using 'at least mild depression' as a cutoff point, and with psychiatric diagnosis. It was also more sensitive and specific than the 15-item Geriatric Depression Scale in detecting depression in the nursing home population [16]. Data about presence of pain were obtained from the MDS item J2a with options of 'no', 'less than daily' and 'daily'. Demographic data were also obtained from the MDS.

\section{Analyses}

We investigated the longitudinal relationship between changes in rejection of care and behaviors directed towards others, and changes in lack of understanding, pain, depression and psychotic symptoms with the structural equation modeling approach. Within this approach, we used latent growth models, bivariate latent growth models and longitudinal latent growth mediation models. Since the studied variables were ordinal, we used latent growth models for categorical variables $[17,18]$ to study change within each variable. This model assumes the existence of latent or nonobserved trajectories, which are observed only indirectly through the repeated measures. The model allows the trajectories to differ by individual case. The intercept represents the initial level at the beginning of the study, and the slope represents the rate of change. The intercept is constant over time and is therefore fixed to one. The factor loadings for the slope represent the measurement points, and they were set to the values $0,3,6$ and 9 that represent the months at which the measurements were taken.

First, we estimated separate latent growth models for each variable. Second, we used bivariate latent growth curve models [17-20] to study the relationships between rejection of care and understanding, and rejection of care and depression. These models combine two latent growth curve models that describe two separate longitudinal processes, and study the relationship between the initial level of the first process (Y, e.g. rejection of care) with the initial level and rate of change in the second process (X, e.g. lack of understanding), and the relationship between the rate of change in the first process with the initial level and rate of change in the second process (fig. 1, process Y and X). Single-headed arrows indicate the direction of the relationship. Bivariate latent growth curve models were also used to describe the relationship between behavioral symptoms directed toward others with rejection of care and behavioral symptoms directed towards others with understanding, and depression.

Frequency distributions of the variables psychotic symptoms and presence of pain remained stable through the whole measurement period, and the latent growth models showed no trend. Therefore, we did not use bivariate latent growth models but latent growth models that included these variables as time-dependent covariates. In the model for psychosis symptoms, we included only the measurements of the first and the fourth psychosis symptom because of the high correlation between the first and the second measurement, and the third and the fourth measurement. 


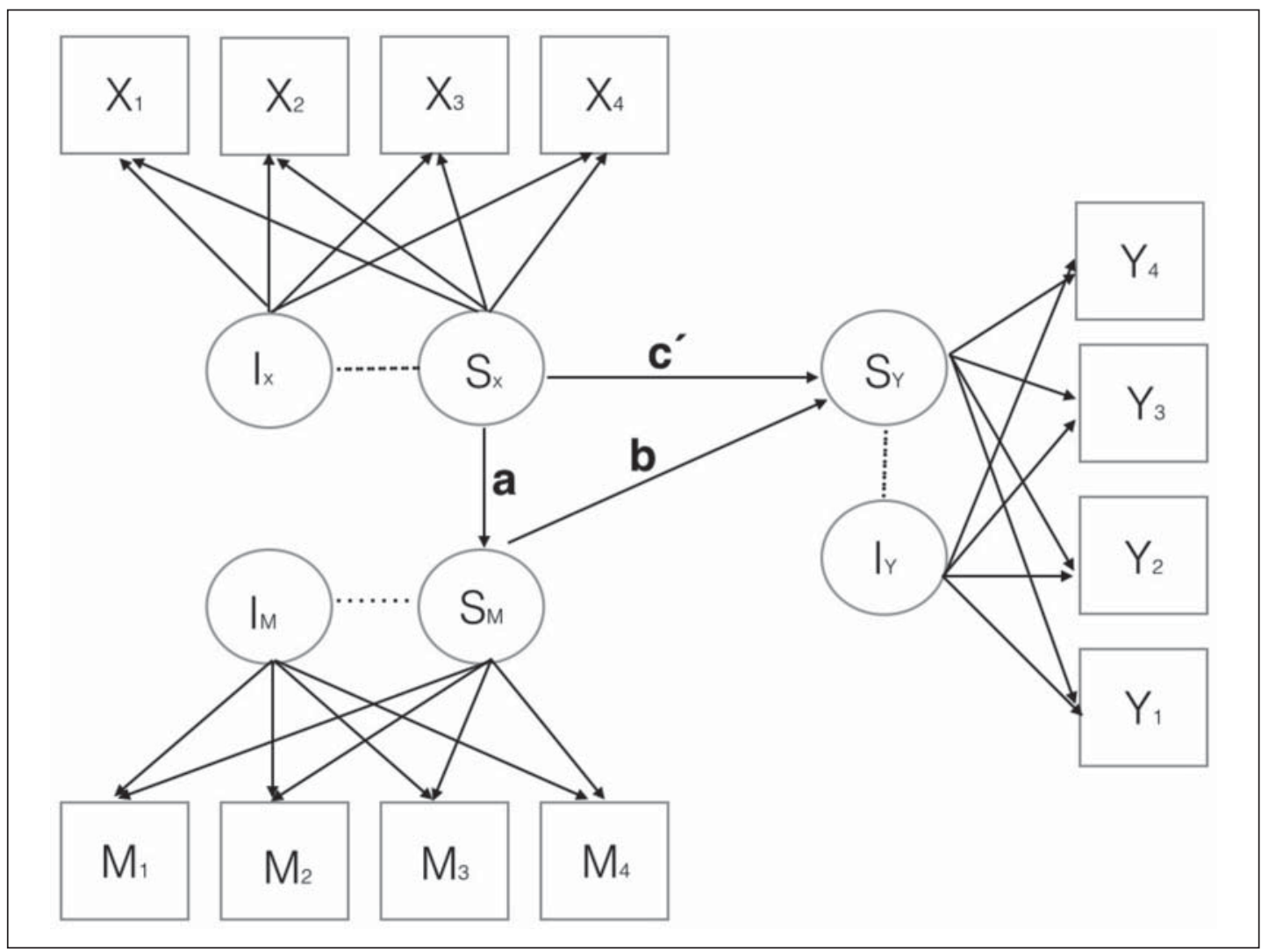

Fig. 1. Path diagram of a latent growth curve mediation model. Squares represent observed repeated measures, ovals represent latent intercepts (I) and latent slopes (S). One-way straight arrows represent both relationships between observed and latent variables and relationships between latent variables, and discontinuous lines represent correlations between latent variables. In the final models, $\mathrm{X}$ represents the independent variables, which are lack of understanding or depression, $\mathrm{M}$ represents the mediator, which is rejection of care, and Y represents the dependent variable, behaviors directed toward others. The relationship between $\mathrm{X}$ and $\mathrm{M}$ is described by $\mathrm{a}$, the relationship between the $\mathrm{M}$ and $\mathrm{Y}$ is described by $\mathrm{b}$, and the direct effect $c^{\prime}$ describes the relationship between $\mathrm{X}$ and $\mathrm{Y}$ that is independent of the mediator $\mathrm{M}$.

Finally, longitudinal mediation models [21] were used to study whether rejection of care mediated the relationship between lack of understanding and behaviors directed towards others, and whether it mediated the relationship between depression and behaviors directed towards others (fig. 1). This means that first changes in lack of understanding (depression) occurred, and they promoted changes in rejection of care. Next, changes in behaviors directed towards others occurred as a consequence of changes in rejection of care. Three sets of latent growth factors were specified, one set for the independent variable, one set for the mediator, and, finally, another set for the dependent variable. The mediation model examined whether the growth in the independent variable affected the growth trajectory of the mediating variable which, in turn, affected the growth trajectory of the dependent variable. The $\chi^{2}$ value, the root mean square error of approximation (RMSEA), the comparative fit index (CFI), and the Tucker-Lewis (TLI) index were used to evaluate the model. A model achieves a good fit if the RMSEA is lower than 0.05, and fit is acceptable for values between 0.05 and 0.09 . An RMSEA of 0.1 or more indicates a poor fit. A CFI and a TLI higher than 0.95 indicate a good fit. All the analyses were performed with the software package Mplus, version 7.1 [22]. Paired $t$ tests were used to assess changes in medication. 
Table 1. Characteristics of the subject population at the beginning of the study $(\mathrm{n}=$ 1,101)
Galindo-Garre et al.: Factors Related to Rejection of Care and Behaviors Directed towards Others: A Longitudinal Study in Nursing Home Residents with Dementia

\begin{tabular}{lc}
\hline Age, years & $84.2 \pm 7.1$ \\
Female & $780(70.8)$ \\
Diagnosis & \\
Alzheimer's disease & $493(44.8)$ \\
Other dementias & $30(2.6)$ \\
Both & $690(62.7)$ \\
Resists care & $316(28.7)$ \\
None & $95(8.6)$ \\
1-3 days in last 7 days & \\
4-6 days, but less than daily & $759(68.9)$ \\
Verbally behavioral symptoms & $241(21.9)$ \\
None & $101(9.2)$ \\
1-3 days in last 7 days & \\
4-6 days, but less than daily & $929(84.4)$ \\
Physically behavioral symptoms & $133(12.1)$ \\
None & $39(3.5)$ \\
1-3 days in last 7 days & $136(12.4)$ \\
4-6 days, but less than daily & \\
Clinical diagnosis of depression & $539(49.0)$ \\
MDS depression score & $562(51.0)$ \\
0-2 & \\
3 or higher & $40(3.6)$ \\
Psychosis & $81(7.3)$ \\
Delusions only & $46(4.2)$ \\
Hallucinations only & \\
Both & \\
Pain & \\
None & \\
Mild & \\
Moderate & $262(51)$ \\
Excruciating at times & \\
Medications administered daily & \\
Antipsychotics & \\
Antidepressants & \\
Antianxiety medications & \\
\hline & \\
\hline
\end{tabular}

\section{Results}

The residents were mostly female, and some had diagnoses of both Alzheimer's disease and other dementias (table 1). Over one third of them exhibited rejection of care for at least some days, and almost one third exhibited verbal behavioral symptoms directed towards others, while about $15.0 \%$ exhibited physical behavioral symptoms directed towards others. About half of these residents (51.0\%) exhibited significant symptoms indicating depression, but only $12.4 \%$ had a clinical diagnosis of depression. Psychotic symptoms were present in $15.1 \%$ of residents, while almost one half of them experienced some pain (table 1).

Most common medications used for treatment of residents with rejection of care and behaviors directed towards others were antipsychotics that were administered at the beginning of the study to $32.2 \%$ of subjects (table 1). Antidepressants were used in $18.7 \%$ of subjects, and antianxiety medications were used in $13.7 \%$ of subjects. Further, all three classes of psychotropic medications were used more often in residents with depressive symptoms than in residents without depression (antipsychotics 27.5 vs. $44.0 \%$, antidepressants 13.0 vs. $27.4 \%$, antianxiety 10.2 vs. $19.6 \%$ ). The prevalence of psychotropic drug admin- 
Table 2. Longitudinal trajectories of measured variables

\begin{tabular}{|c|c|c|c|c|c|c|c|c|c|c|}
\hline \multirow[t]{2}{*}{ Variable } & \multicolumn{4}{|c|}{ Model fit ${ }^{1}$} & \multicolumn{6}{|l|}{ Slope } \\
\hline & $\chi^{2}$ & d.f. & $\mathrm{p}$ & RMSEA & mean & SE & $\mathrm{p}$ & Var & SE & $\mathrm{p}$ \\
\hline Lack of understanding & 10.3 & 8 & 0.244 & 0.016 & 0.078 & 0.045 & $<0.001$ & 0.014 & 0.001 & $<0.001$ \\
\hline Depression & 28.2 & 5 & $<0.001$ & 0.065 & 0.06 & 0.01 & $<0.001$ & 0.023 & 0.003 & $<0.001$ \\
\hline Psychosis & - & & & & - & & & & & \\
\hline Pain & 10.5 & 2 & $<0.001$ & 0.062 & 0.023 & 0.015 & 0.111 & 0.057 & 0.019 & 0.003 \\
\hline Rejection of care & 15.4 & 5 & 0.009 & 0.04 & 0.058 & 0.01 & $<0.001$ & 0.026 & 0.003 & $<0.001$ \\
\hline \multicolumn{11}{|c|}{ Behavior directed towards others } \\
\hline (abusive behaviors) & 26.0 & 11 & 0.006 & 0.035 & 0.014 & 0.04 & $<0.001$ & 0.004 & 0.000 & $<0.001$ \\
\hline
\end{tabular}

Positive slopes indicate that these symptoms increase with time. The model for psychosis could not be estimated.

${ }^{1} \mathrm{CFI}$ and TLI indices were equal to one for all models.

istration did not change during the study for antipsychotics $(\mathrm{t}=0.22, \mathrm{p}=0.826)$ and antidepressants $(\mathrm{t}=-0.81, \mathrm{p}=0.416)$, while the use of antianxiety medications increased (13.7 vs. $17.3 \%, \mathrm{t}=-2.51, \mathrm{p}=0.012$ ).

\section{Longitudinal Trajectories of Each Process}

Table 2 shows the longitudinal trajectories of all the variables analyzed with latent growth models to investigate the development of the symptoms over time. Based on the RMSEA criteria, the model fit was good for the lack of understanding, rejection of care and behaviors directed towards others, and acceptable for depression and pain. The CFI and TLI coefficients were equal to one for all the models. In table 2, positive slopes show that all these variables increased with time. However, the increase was not significant for pain. The latent growth model for psychosis symptoms could not be estimated because there were almost no cases with change in psychosis scores within the study period.

\section{Combined Longitudinal Relationships}

Next, bivariate linear latent growth models were used to study the relationships between evolution in rejection of care and evolution in symptoms related to rejection of care. For psychosis and pain, we fitted a model with these variables as time-dependent covariates because previously estimated latent growth models did not show evidence of change for these variables. The model fit columns in table 3 show low RMSEA values indicating a good model fit. The CFI and TLI coefficients were equal to one.

Table 3 also reports the relationship between the slopes. Changes in rejection of care were associated with or can be predicted by changes in lack of understanding and also by changes in depression. Finally, lower initial levels of pain were associated with a stronger increase in rejection of care ( $c=-0.009, \mathrm{SE}=0.004, \mathrm{p}=0.029)$.

The relationships between the intercepts or initial level of rejection of care and intercepts of the other variables are not reported in table 3 because intercept parameters depend on the measurement scale of the analyzed variables. The relationships between psychosis symptoms and pain, and initial levels of rejection of care are scale free and can be interpreted. We found a strong relationship between psychosis and initial levels of rejection of care, with higher initial levels of psychosis associated with higher initial levels of rejection of care $(c=0.207$, $\mathrm{SE}=0.053, \mathrm{p}<0.001)$. We also found that high initial levels of pain were associated with high initial levels of rejection of care ( $c=0.116, \mathrm{SE}=0.045, \mathrm{p}=0.009$ ). 
Table 3. Bivariate linear latent growth curve models

\begin{tabular}{|c|c|c|c|c|c|c|c|}
\hline \multirow[t]{2}{*}{ Predictors } & \multicolumn{4}{|c|}{ Model fit ${ }^{1}$} & \multicolumn{3}{|c|}{ Relationship between slopes } \\
\hline & $\chi^{2}$ & d.f. & $\mathrm{p}$ & RMSEA & $\mathrm{B}$ & SE & $\mathrm{p}$ \\
\hline \multicolumn{8}{|l|}{ Outcome: rejection of care } \\
\hline Lack of understanding & 36.4 & 25 & 0.066 & 0.020 & 0.699 & 0.167 & $<0.001$ \\
\hline Depression & 47.4 & 23 & 0.002 & 0.031 & 0.811 & 0.134 & $<0.001$ \\
\hline Psychosis symptoms & 15.8 & 7 & 0.003 & 0.034 & & & \\
\hline Pain & 23.35 & 9 & 0.005 & 0.038 & & & \\
\hline \multicolumn{8}{|c|}{ Outcome: behaviors directed toward others (abusive behaviors) } \\
\hline Rejection of care & 59.2 & 28 & 0.005 & 0.032 & 0.718 & 0.093 & $<0.001$ \\
\hline Lack of understanding & 38.7 & 25 & 0.039 & 0.022 & 0.175 & 0.083 & 0.035 \\
\hline Depression & 65.8 & 28 & 0.001 & 0.035 & 0.630 & 0.094 & $<0.001$ \\
\hline Psychosis symptoms & 33.8 & 13 & 0.001 & 0.038 & & & \\
\hline Pain & 32.7 & 15 & 0.005 & 0.033 & & & \\
\hline
\end{tabular}

Parameter estimates for pain and psychosis symptoms are not included in the table because these variables were included as time-dependent covariate in the model.

${ }^{1} \mathrm{CFI}$ and TLI indices were equal to one for all models.

Then, bivariate linear latent growth models were used to describe the relationships between evolution in behaviors directed towards others and evolution in symptoms related to those behaviors. A low RMSEA indicated a good model fit (see table 3). The columns reporting relationships between slopes show significant positive relationships between changes in rejection of care and changes in behaviors directed towards others. Changes in understanding and changes in depression were also associated with changes in behaviors directed towards others.

The relationships between intercepts for behaviors directed towards others are not reported in table 3 because of the same reasons explained above for the rejection of care analyses. Regarding the relationship between initial behaviors directed towards others and initial levels in pain or psychotic symptoms, we found a significant relationship between initial behaviors directed towards others and initial psychosis $(c=0.205, \mathrm{SE}=0.051, \mathrm{p}<$ 0.001 ), indicating that initial psychosis was related to more frequent behaviors directed toward others.

\section{Mediated Effects}

Finally, we built the two mediation models (fig. 1), one to investigate whether rejection of care mediated the relationship between lack of understanding and behaviors directed towards others, and the other to investigate whether rejection of care mediated the relationship between depression and behaviors directed towards others. We used the longitudinal growth mediation described in MacKinnon [21, chapter 8]. Consistent with the literature on statistical mediation [21], the parameters illustrating the relationships in figure 1 are called $\mathrm{a}, \mathrm{b}$ and $\mathrm{c}^{\prime}$. Parameter a describes the relationship between the slope for the independent variable $(\mathrm{X})$ and the slope for the mediator $(\mathrm{M})$. Parameter $\mathrm{b}$ describes the relationship between the slope of the mediator (M) and the slope in the dependent variable (Y). Parameter $c^{\prime}$ represents the direct effect, which is the part of the effect of $\mathrm{X}$ on $\mathrm{Y}$ that is independent of the mediator. This parameter has a prime sign to reflect the adjustment for the mediator.

The fit of the first model was good $\left(\chi^{2}\right.$ test $=88.6$, d.f. $=61, p=0.012$, RMSEA $=0.021$, $\mathrm{CFI}=1.000$, TLI $=1.000)$. The relationship between lack of understanding and rejection of 
Galindo-Garre et al.: Factors Related to Rejection of Care and Behaviors Directed

Fig. 2. Path diagram describing the results obtained with the mediation models.

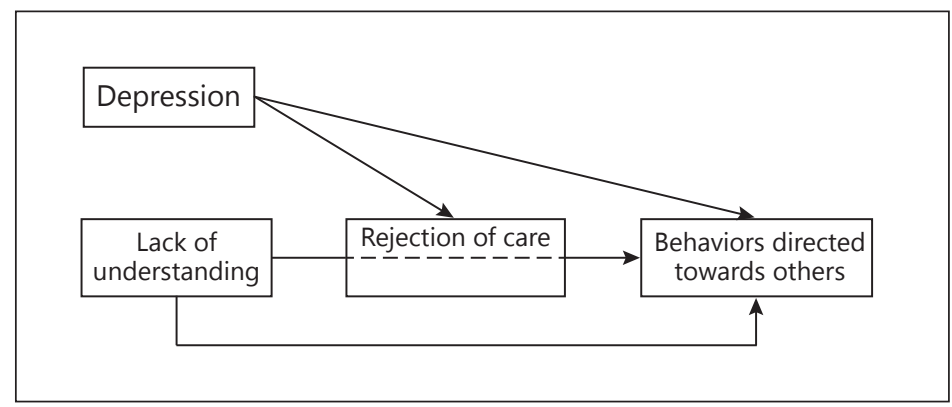

care was significant $(\mathrm{a}=0.876, \mathrm{SE}=0.124, \mathrm{p}<0.000$ ). There was a significant relationship between rejection of care and behaviors directed towards others $(b=1.249, \mathrm{SE}=0.337, \mathrm{p}<$ 0.001 ), while the relationship between lack of understanding and behaviors directed towards others after adjusting for rejection of care was not significant $\left(c^{\prime}=-0.645, \mathrm{SE}=0.465, \mathrm{p}=\right.$ $0.166)$. Therefore, this model suggests that the relationship between lack of understanding and behaviors directed towards others is mediated by rejection of care. To quantify the indirect effect, the product of the parameters $a$ and $b$ was calculated and tested with the Sobel test. We found a significant mediation effect $(\mathrm{ab}=0.979, \mathrm{SE}=0.440, \mathrm{p}=0.026$, with ab being the change in the outcome per one unit lack of understanding that goes through the mediator rejection of care; fig. 2).

The fit of the second model was also good $\left(\chi^{2}\right.$ test $=105.1$, d.f. $=58, p=0.0002$, RMSEA $=$ $0.027, \mathrm{CFI}=1.000$, TLI $=1.000$ ). The relationship between the slope for depression and the slope for rejection of care was significant $(a=0.828, S E=0.138, p<0.001)$, but there was not significant evidence that the slope in the mediator rejection of care was associated with the slope in behaviors directed towards others $(b=0.561, \mathrm{SE}=0.306, \mathrm{p}=0.067)$. The adjusted direct effect $\left(c^{\prime}=0.427, S E=0.343, p=0.214\right)$ and the indirect effect were also not significant $(\mathrm{ab}=0.465, \mathrm{SE}=0.277, \mathrm{p}=0.094)$. Therefore, we cannot conclude that the relationship between depression and behaviors directed towards others is mediated by rejection of care. Since we did not observe changes in psychosis and pain, we did not consider mediation models for these processes.

\section{Discussion}

The results of this longitudinal study showed that changes in lack of understanding or depression commonly precede changes in rejection of care. Changes in behaviors directed towards others are related to changes in lack of understanding, depression and rejection of care. Furthermore, a mediation model suggested that the relationship between lack of understanding and behaviors directed towards others was mediated by rejection of care. Therefore, our results support conclusions of our previous cross-sectional study [13], which found that lack of understanding and depression are the two main risk factors for development of rejection of care and behaviors directed towards others. However, our results are more informative because longitudinal models provide more information regarding temporal relationships between the variables, and the mediation model provides information about the order in which the symptoms develop.

Initial psychotic symptoms and pain were also related to increased rejection of care, but we did not observe changes in the number of psychotic symptoms and pain within our study period. Regarding to the absence of observed changes in pain, Hendriks et al. [23] found a high 
proportion of patients with pain persistence. That precluded inclusion of psychotic symptoms and pain in the mediation model. A relationship of depression to resistive behavior (rejection of care) and aggression (abusive symptoms) was already reported by Lyketsos et al. [24] and by Leonard et al. [25]. They found, in agreement with our results, that psychotic symptoms play a minor role in the development of these behaviors.

The lack of understanding is caused by the progression of dementia, and it increases the prevalence of rejection of care [26]; this increase in rejection of care contributes to the increasing behaviors directed towards others. It may be improved by communication skills training of professionals and family caregivers that includes verbal skills, nonverbal and emotional skills, behavioral management skills, usage of tools and theoretical knowledge [27]. Such a program would be useful also in a hospital where many dementia patients are transferred [28]. The most important intervention is to teach the staff that most people with dementia are not aggressive; they just defend themselves against unwanted attention from the caregivers and may consider the caregivers to be the aggressors. Labeling somebody who is combative during care an 'aggressor' is blaming the victim. Similarly, this person should not be labeled as agitated. There is a clear-cut distinction between rejection of care and agitation [26], and the term agitation should be reserved for behaviors that occur when the resident is solitary, e.g. restlessness, repetitive movements, crying out [29].

We identified depressive symptoms using the MDS depression scale [16], which uses 7 MDS items. This scale correlated well with the Cornell and Hamilton depression scales using 'at least mild depression' as a cutoff point, and with psychiatric diagnosis. The MDS depression scale detected significant depressive symptoms in $51 \%$ of the subject population. This is comparable to $47.4 \%$ detected in a large study of a long-term care facility [30]. High prevalence of depression in individuals with Alzheimer's disease can be expected because Alzheimer's disease causes serotoninergic deficit, and some data indicate that this deficit may be related to aggressive behaviors [31,32]. The relationship between serotoninergic function and aggressive behavior may not be unique to Alzheimer's disease because decreased serotoninergic activity is present also in frontotemporal dementia [33].

Our results suggest that depression contributes to both rejection of care and behaviors directed towards others and that the relation between depression and behaviors towards others is not mediated by rejection of care. Depression in dementia could be treated with psychological interventions as shown in a recent review [34]. Antidepressants could be the first line of medication for individuals exhibiting these behaviors directed towards others if psychotic symptoms are not present. Although some studies found improvement of behavioral symptoms after treatment with antidepressants [35, 36], other studies were negative. This was probably due to insufficient doses and duration of treatment. This was documented by the Depression in Alzheimer Disease Study, which found that treatment with sertraline decreased behavioral disturbance and caregiver distress only in patients whose depression responded to antidepressant treatment [37]. Antidepressant treatment was found effective in decreasing behavioral symptoms of dementia in a Cochrane data analysis [38] and in a recent citalopram study [10], but antidepressants may sometimes require augmentation with atypical antipsychotics [39].

The results of this study show that the psychotropic medications administered most frequently to the participants in this study were antipsychotics. It is possible that these drugs somewhat reduced rejection of care by their sedative effects. Similar prevalences of antipsychotic use were reported from a survey of nursing home physicians in the US [4] and a Dutch survey [40]. In that study, $32 \%$ of subjects received antipsychotics, which is comparable with reports from Sweden (38\%) [41] and from Germany (32.5\%) [42]. Antipsychotics are used frequently for treatment of behavioral symptoms of dementia despite multiple reports that found serious side effects including increased mortality in residents treated with these medi- 
cations [43]. Side effects of antipsychotics may be more serious in older men [44]. Efforts are made in several countries to decrease the use of antipsychotics in dementia. In the US, the prevalence of antipsychotic use in nursing homes is about $25 \%$ [45], and the use of antipsychotics was recently reduced by $9.1 \%$ [46]. In the UK, antipsychotic use in people with dementia decreased from $19.9 \%$ in 1995 to $7.4 \%$ in 2011, concomitant with an increase of antidepressants from 10.7 to $25.3 \%$ [47], indicating that antidepressants may be substituted for antipsychotics.

This study has several limitations. Our data were derived from MDS records that were completed mostly by nurses. However, these were experienced clinicians, and MDS data correlated well with other scales [48]. We have studied the relationship of only four factors in abusive behavior of nursing home residents with dementia. However, there are probably also other factors that may be involved, e.g. physical causes such as thirst, hunger or inappropriate environmental temperature. Using a discomfort scale [49] in future studies would provide information about the importance of these other factors. Our data could not evaluate these causes. A model with all predictors controlling for the influence of each variable would provide more evidence for causality than our models. Another limitation is that we did not have data about specific drugs and drug dosages that may have been modified in residents with rejection of care and behaviors directed towards others even when the prevalence of their use did not change.

\section{Conclusions}

The results of this study together with the results of previous investigations [13, 24-26] indicate that lack of understanding and depression are important factors in development of rejection of care and behaviors directed towards others, and that rejection of care may escalate into behaviors directed towards others. Initial psychotic symptoms and pain may also play a role. Furthermore, the relationship between lack of understanding and behaviors directed towards others may be mediated by rejection of care. Therefore, improved communication between caregivers and persons with dementia and perhaps also effective treatment of depression may prevent or ameliorate rejection of care and behaviors directed towards others.

\section{Acknowledgement}

We thank Dr. Dinnus H.M. Frijters for compiling the dataset. This study was supported by the Department of Epidemiology and Biostatistics, VU University Medical Center Amsterdam, and by an Aspasia supplement to a career award for J.T.v.d.S. of the Netherlands Organisation for Scientific Research (Innovational Research Incentives Scheme: Vidi grant No. 917.11.339).

\section{Disclosure Statement}

The authors declare that they have no conflicts of interest. 
Galindo-Garre et al.: Factors Related to Rejection of Care and Behaviors Directed towards Others: A Longitudinal Study in Nursing Home Residents with Dementia

\section{References}

1 Morgan DG, Cammer A, Stewart NJ, Crossley M, D'Arcy C, Forbes DA, Karunanayake C: Nursing aids reports of combative behavior by residents with dementia: results form a detailed prospective diary. J Am Med Dir Assoc 2012;13:220-227.

-2 Afram B, Stephan A, Verbeek H, Bleijlevens MH, Suhonen R, Sutcliffe C, Raamat K, Cabrera E, Soto ME, Hallberg IR, Meter G, Hamers JP: Reasons for institutionalization of people with dementia: informal caregiver reports from 8 European countries. J Am Med Dir Assoc 2013;15:108-116.

-3 Phillips VL, Diwan S: The incremental effect of dementia-related problem behaviors on the time to nursing home placement in poor, frail, demented older people. J Am Geriatr Soc 2003;51:188-193.

$>4$ Cohen-Mansfield J, Jensen B: Assessment and treatment approaches for behavioral disturbances associated with dementia in the nursing home: self-reports of physicians' practices. J Am Med Dir Assoc 2008;9:406-413.

5 Husebo BS, Ballard C, Sandvik R, Nilsen OB, Aarsland D: Efficacy of treating pain to reduce behavioral disturbances in residents of nursing homes with dementia: cluster randomized clinical trial. BMJ 2011;343:d4065.

6 Ballard C, Brown R, Fossey J, et al: Brief psychosocial therapy for the treatment of agitation in Alzheimer disease (the CALM-AD trial). Am J Geriatr Psychiatry 2009;17:726-733.

7 Cohen-Mansfiel J, Werner P, Marx MS: An observational study of agitation in agitated nursing home residents. Int Psychogeriatrics 1989;1:153-165.

-8 Cummings JL, Mega M, Gray K, Rosenberg-Thompson S, Carusi DA, Gornbein J: The neuropsychiatric inventory: comprehensive assessment of psychopathology in dementia. Neurology 1994;44:2308-2314.

9 Volice L: What is NPI item 'Agitation/Aggression' really measuring? Am J Geriatr Psychiatry 2011;19:1046.

$\checkmark 10$ Porsteinsson AP, Drye LT, Pollock BG, et al: Effect of citalopram on agitation in Alzheimer disease: the CitAD randomized clinical trial. JAMA 2014;311:682-691.

11 Sultzer DL, Davis SM, Tariot PN, et al: Clinical symptom responses to atypical antipsychotic medications in Alzheimer's disease: phase 1 outcomes from the CATIE-AD effectiveness trial. Am J Psychiatry 2008;165: 844-854.

12 Ishii S, Streim JE, Saliba D: A conceptual framework for rejection of care behaviors: review of literature and analysis of role of dementia severity. J Am Med Dir Assoc 2012;13:11-23.

$\$ 13$ Volicer L, Van der Steen JT, Frijters D: Modifiable factors related to abusive behaviors in nursing home residents with dementia. J Am Med Dir Assoc 2009;10:617-622.

14 Morris JN, Hawes C, Fries BE, Phillips CD, Mor V, Katz S, Murphy K, Drugovich ML, Friedlob AS: Designing the national resident assessment instrument for nursing homes. Gerontologist 1990;30:293-307.

15 Siem C, Rantz M: Operationalizing the MDS 3.0 in the nursing home. J Am Med Dir Assoc 2013;14:445-446.

16 Burrows AB, Morris JN, Simon SE, Hirdes JP, Phillips C: Development of a Minimum Data Set-based depression rating scale for use in nursing homes. Age Ageing 2000;29:165-172.

17 Bollen KA, Curran PJ: Latent Curve Models: A Structural Equation Approach. Wiley Series on Probability and Mathematical Statistics. New Jersey, John Wiley \& Sons, 2006.

18 Mehta PD, Neale MC, Flay BR: Squeezing interval change from ordinal panel data: latent growth curves with ordinal outcomes. Psychol Methods 2004;9:301.

19 McArdle JJ: Dynamic but structural equation modeling of repeated measures data; in Nesselroade JR, Cattell RB (eds): Handbook of Multivariate Experimental Psychology. New York, Springer, 1988, pp 561-614.

20 Grimm KJ: Multivariate longitudinal methods for studying developmental relationships between depression and academic achievement. Int J Behav Dev 2007;31:328-339.

21 MacKinnon DP: Introduction to Statistical Mediation Analysis. New York, Taylor \& Francis Group LLC, 2008.

22 Muthén LK, Muthén BO: Mplus Statistical Analysis with Latent Variables, User’s Guide. Los Angeles, Muthén \& Muthén, 2010.

23 Hendriks SA, Smalbrugge M, Galindo-Garre F, Hertogh CMPM, van der Steen JT: From admission to death: prevalence and course of pain, agitation, and shortness of breath, and treatment of these symptoms in nursing home residents with dementia (abstract). Eur Geriatr Med 2014;5(suppl 1):S46-S47.

24 Lyketsos CG, Steele C, Galik E, Rosenblatt A, Steinberg M, Warren A, Sheppard JM: Physical aggression in dementia patients and its relationship to depression. Am J Psychiatry 1999;156:66-71.

25 Leonard R, Tinetti ME, Allore HG, Drickamer MA: Potentially modifiable resident characteristics that are associated with physical or verbal aggression among nursing home residents with dementia. Arch Intern Med 2006;166:1295-1300.

-26 Volicer L, Bass EA, Luther SL: Agitation and resistiveness to care are two separate behavioral syndromes of dementia. J Am Med Dir Assoc 2007;8:527-532.

27 Eggenberger E, Heimerl K, Bennettt MI: Communication skills training in dementia care: a systematic review of effectiveness, training content, and didactic methods in different care settings. Int Psychogeriatr 2013;25: 345-358.

28 Elvish R, Burrow S, Cawley R, et al: 'Getting to Know Me': the development and evaluation of a training program for enhancing skills in the care of people with dementia in general hospital settings. Aging Ment Health 2014; 18:481-488.

29 Hurley AC, Volicer L, Camberg L, Ashley J, Woods P, Odenheimer G, Ooi WL, McIntyre K, Mahoney E: Measurement of observed agitation in patients with Alzheimer's disease. J Mental Health Aging 1999;5:117-133. 
Galindo-Garre et al.: Factors Related to Rejection of Care and Behaviors Directed

30 Parmelee PA, Katz IR, Lawton MP: Depression among institutionalized aged: assessment and prevalence estimation. J Gerontol A Biol Sci Med Sci 1989;44:22-29.

-31 Pritchard AL, Harris J, Pritchard CW, Coates J, Hague S, Holder R, et al: Role of 5HT 2A and 5HT 2C polymorphisms in behavioral and psychological symptoms of Alzheimer's disease. Neurobiol Aging 2008;29:341-347.

-32 Pritchard AL, Pritchard CW, Bentham P, Lendon CL: Role of serotonin transporter polymorphisms in the behavioral and psychological symptoms in probable Alzheimer disease patients. Dement Geriatr Cogn Disord 2007;24:201-206.

33 Huey ED, Putnam KT, Grafman J: A systematic review of neurotransmitter deficits and treatments in frontotemporal dementia. Neurology 2006;66:17-22.

-34 Ortega V, Qazi A, Spector AE, Orrell M: Psychological treatments for depression and anxiety in dementia and mild cognitive impairment. Cochrane Database Syst Rev 2014;CD009125.

-35 Finkel SI, Mintzer JE, Dysken M, Krishnan KR, Burt T, McRae T: A randomized, placebo-controlled study of the efficacy and safety of sertraline in the treatment of the behavioral manifestations of Alzheimer's disease in outpatients treated with donepezil. Int J Geriatr Psychiatry 2004;19:9-18.

36 Pollock BG, Mulsant BH, Rosen J, Sweet RA, Mazumdar S, Bharucha A, Marin R, Jacob NJ, Huber KA, Kastango $\mathrm{KB}$, Chew ML: Comparison of citalopram, perphenazine, and placebo for the acute treatment of psychosis and behavioral disturbances in hospitalized, demented patients. Am J Psychiatry 2002;159:460-465.

-37 Lyketsos CG, DelCampo L, Steinberg M, Miles Q, Steele CD, Munro C, Baker AS, Sheppard JME, Frangakis C, Brandt J, Rabins PV: Treating depression in Alzheimer disease - efficacy and safety of sertraline therapy, and the benefits of depression reduction: the DIADS. Arch Gen Psychiatry 2003;60:737-746.

-38 Seitz DP, Adunuri N, Gill SS, Gruneir A, Herrmann N, Rochon P: Antidepressants for agitation and psychosis in dementia. Cochrane Database Syst Rev 2011;CD008191.

-39 Papakostas GI, Shelton RC, Smith J, Fava M: Augmentation of antidepressants with atypical antipsychotic medications for treatment-resistant major depressive disorder: a meta-analysis. J Clin Psychiatry 2007;68: 826-831.

40 Cornege-Blockland E, Kleijer BC, Hertogh CM, van Marum RJ: Reasons to prescribe antipsychotics for the behavioral symptoms of dementia: a survey in Dutch nursing homes among physicians, nurses, and family caregivers. J Am Med Dir Assoc 2012;13:80.

41 Gustafsson M, Karlsson S, Lovheim H: Inappropriate long-term use of antipsychotic drugs is common among people with dementia living in specialized care units. BMC Pharmacol Toxicol 2013;14:10.

42 Morley JE: Antipsychotics and dementia: a time for restraint? J Am Med Dir Assoc 2012;13:761-763.

-43 Schulze J, van den Bussche H, Glaeske G, Kaduszkiewics H, Wiese BHF: Impact of safety warnings on antipsychotic prescriptions in dementia: nothing has changed but the years and the substances. Eur Neuropsychopharmacol 2013;23:1034-1042.

-44 Ballard C, Creese B, Corbett A, Aarsland D: Atypical antipsychotics for the treatment of behavioral and psychological symptoms in dementia, with a particular focus on longer term outcomes and mortality. Expert Opin Drug Saf 2012;10:35-43.

45 Rochon PA, Gruneir A, Gill SS, Wu W, Fischer HD, Bronskill SE, et al: Older men with dementia are at greater risk than women of serious events after initiating antipsychotic therapy. J Am Geriatr Soc 2013;61:55-61.

46 Centers for Medicare and Medicaid Services: New Data Show Antipsychotic Drug Use Is Down in Nursing Homes Nationwide. Baltimore, Centers for Medicare and Medicaid Services, 2013.

47 Martinez C, Jones RW, Rietbrock S: Trends in the prevalence of antipsychotic drug use among patients with Alzheimer's disease and other dementias including those treated with antidementia drugs in the community in the UK: a cohort study. BMJ Open 2013;3:e002080.

48 Fredericksen K, Tariot P, De Jonghe E: Minimum Data Set Plus (MDS+) scores compared with scores from five rating scales. J Am Geriatr Soc 1996;44:305-309.

49 Hurley AC, Volicer BJ, Hanrahan P, Houde S, Volicer L: Assessment of discomfort in advanced Alzheimer patients. Res Nurs Health 1992;15:369-377. 